\title{
Divorce in the barn owl: securing a compatible or better mate entails the cost of re-pairing with a less ornamented female mate
}

\author{
A. N. DREISS \& A. ROULIN \\ Department of Ecology and Evolution, University of Lausanne, Lausanne, Switzerland
}

Keywords:

barn owl;

breeding success;

divorce;

female ornament;

incompatibility hypothesis;

melanin.

\begin{abstract}
Two nonmutually exclusive hypotheses can explain why divorce is an adaptive strategy to improve reproductive success. Under the 'better option hypothesis', only one of the two partners initiates divorce to secure a higherquality partner and increases reproductive success after divorce. Under the 'incompatibility hypothesis', partners are incompatible and hence they may both increase reproductive success after divorce. In a long-term study of the barn owl (Tyto alba), we address the question of whether one or the two partners derive fitness benefits by divorcing. Our results support the hypothesis that divorce is adaptive: after a poor reproductive season, at least one of the two divorcees increase breeding success up to the level of faithful pairs. By breeding more often together, faithful pairs improve coordination and thereby gain in their efficiency to produce successful fledglings. Males would divorce to obtain a compatible mate rather than a mate of higher quality: a heritable melanin-based signal of female quality did not predict divorce (indicating that female absolute quality may not be the cause of divorce), but the new mate of divorced males was less melanic than their previous mate. This suggests that, at least for males, a cost of divorce may be to secure a lower-quality but compatible mate. The better option hypothesis could not be formally rejected, as only one of the two divorcing partners commonly succeeded in obtaining a higher reproductive success after divorce. In conclusion, incompatible partners divorce to restore reproductive success, and by breeding more often together, faithful partners improve coordination.
\end{abstract}

\section{Introduction}

Most bird species are socially monogamous (Lack, 1968), with the two partners sharing exclusive reproductive activities including nest building and parental care. This association can persist over lifetime or be limited to one or a few reproductive events (Rowley, 1983). Individuals can change mate either because their partner has died or because they divorce. Divorce is defined as one breeding individual changing partner for a new mate while the previous mate is still alive (Coulson, 1972; Rowley, 1983; Ens et al., 1993).

Studying the adaptive function of divorce as well as of long-term monogamy has been the focus of intense

Correspondence: Alexandre Roulin, Department of Ecology and Evolution, University of Lausanne, Biophore, CH-1015 Lausanne, Switzerland. Tel.: +41 796860 864; fax: +41 216924 165; e-mail: Alexandre.Roulin@unil.ch research (Choudhury, 1995; Cézilly et al., 2000). These two aspects are intimately connected because divorce may be the mean to secure a higher-quality or compatible partner, while pursuing a pair-bond can gradually improve the efficiency of coordination between partners in reproductive activities (Davis, 1988). Assuming that divorce is adaptive, two major nonmutually exclusive hypotheses have been proposed to explain its occurrence. Under the 'better option hypothesis', divorce is an active choice by only one of the two partners. In this case, the individual that initiated divorce improves its reproductive success by breeding with a higher-quality mate or in a higher-quality territory (Davies, 1989; Ens et al., 1993), while the reproductive success of its 'deserted' mate is unaffected or reduced following divorce. Under the incompatibility hypothesis', divorce is a decision of both partners whose association was suboptimal and resulted in a poor reproductive performance. Consequently, both partners 
could benefit from divorcing in order to pair with a compatible mate (Coulson, 1966, 1972; Rowley, 1983). If the degree of compatibility or coordination between mates improves with experience, reproductive performance should also increase with the duration of pairbond (Coulson, 1966; Black, 2001; van de Pol et al., 2006). Furthermore, because under this hypothesis divorce is elicited by an incompatibility between partners rather than because one of the two partners is of poor quality (as predicted by the 'better option hypothesis'), the new partner of divorced individuals may not necessarily be of higher intrinsic quality than the previous partner but simply more compatible. Therefore, in sexually ornamented species, we can predict under the 'better option hypothesis' that individuals paired with poorly ornamented mate are more likely to divorce than individuals paired with highly ornamented mate (Jones \& Montgomerie, 1991) and that the new partner of individuals that initiate divorce is more extravagantly ornamented than the previous one. In contrast, under the 'incompatibility hypothesis', the new partner may be less ornamented than the previous partner because searching a compatible mate may reduce the mate choice options with respect to an ornament.

We investigated whether the 'better option' or the 'incompatibility' hypotheses could account for divorce in the barn owl Tyto alba, a long-lived monogamous bird. Under the first hypothesis, only one of the two partners increases reproductive success after divorce, whereas under the latter hypothesis the two partners enhance reproductive success. We therefore compared the reproductive success of males and females separately before and after a divorce (Streif \& Rasa, 2001; Dhondt, 2002). We then analysed the quality of mates and territory for males and females before and after divorce. We furthermore examined whether in faithful pairs reproductive success increases with the duration of pair-bond. The barn owl is particularly interesting because pairs are faithful during a breeding event (i.e. very few extra-pair young, Henry et al., 2013) and divorce is hence the principal way to mate with another individual. Moreover, females display on average larger black feather spots than males. There is a pronounced interindividual variation in the size of black spots and it has been repeatedly shown that larger-spotted females have a higher survival and produce higher-quality offspring than smaller-spotted females (Roulin et al., 2010; Roulin \& Ducrest, 2011). Therefore, if the new female mate of divorced males displays larger black spots than the previous mate, this is evidence for the better option hypothesis. In contrast, if divorce is caused by the need to re-pair with a compatible mate (a property that may be independent of spot size), the new mate may be in fact smaller-spotted than the previous mate because mate choice may be limited after a divorce. Although the literature on divorce is important, our study is particularly interesting because it deals with a species with very few extra-pair mating (Henry et al., 2013) (hence divorce is the only possibility to breed with another partner) and presenting a heritable melanin-based melanic ornament that is related to mate choice (Roulin, 1999).

\section{Materials and methods}

\section{Study species}

Barn owls are long-lived, socially monogamous and extra-pair fertilization is rare (Henry et al., 2013). Adults are usually sedentary and begin to search a mate and nest site already in winter (Roulin et al., 1998). This species has a high reproductive potential with birds producing up to two broods per year, each nest containing between 2 and 11 eggs (mean is 6) giving between 1 and 9 fledglings (mean is 4) (Chausson et al., 2014). Offspring sex ratio is 0.497 (Roulin et al., 2010). Survival probability from one year to the next is $17 \%$ in juveniles and $72 \%$ in adults (Altwegg et al., 2003). Barn owls vary in coloration from white to dark reddish pheomelanic and in both number and size of black eumelanic spots. These three traits are heritable $\left(0.80<h^{2}<0.90\right.$, Roulin \& Dijkstra, 2003; Roulin, 2004; Roulin et al., 2010), and although members of each sex can express any phenotype, females are on average darker reddish and display more and larger black spots than males. Females with more and larger black spots are preferred by males (Roulin et al., 2000, 2001), and pairing with respect to spot size is slightly assortative (Roulin, 1999).

\section{Data collection}

Data were collected in a free-living population of barn owls located in western Switzerland $\left(46^{\circ} 49^{\prime} \mathrm{N}, 06^{\circ} 56^{\prime} \mathrm{E}\right.$; 375-850 m above sea level; Frey et al., 2011) between 1988 and 2012. The area is covering $1070 \mathrm{~km}^{2}$ and includes 207 nest boxes where 455 breeding males and 664 breeding females and 5796 nestlings were ringed or controlled. Breeding females were recognized by the presence of a brood patch. On the breast of each individual, plumage was compared with eight colour chips ranging from dark reddish (1) to white (8). On the same body part, black spots were counted within a $80 \times 60 \mathrm{~mm}$ frame and their diameter measured to the nearest $0.1 \mathrm{~mm}$. A mean spot diameter was calculated to be used in the statistical analyses. Assessment of plumage traits is accurate (Roulin, 1999, 2004; Dreiss \& Roulin, 2010). Age was known with precision when individuals had been ringed as nestlings. When breeders had not been ringed as nestlings, we considered them as 'yearlings' ( 1 years old) if all primary and secondary wing feathers belonged to the same generation, as 2 years old if only the sixth primary had already been renewed and as 3 years old if more primary or secondary wing feathers were already renewed (Taylor, 
1993). We obtained a surrogate of offspring body condition by computing the average body mass of all nestmates, measured between 35 and 55 days after hatching, when the body mass is not significantly related to age (Pearson's correlation: $r=0.005$, $P=0.73, N=4096$ young).

To examine whether divorce is more frequent in poor- rather than in high-quality territories, we derived an index of territory quality defined as the occupancy rate of the nest box over the study period, which is good measure of quality (Sergio \& Newton, 2003). In a previous study, we showed that the occupancy rate is related to environmental factors (smaller occupancy rate of nest boxes surrounded by a greater number of roads, Frey et al., 2011). Nest boxes were available during 2-26 years of the 26-year-long study period and occupancy rate ranged from 5 to $100 \%(42 \pm 5 \%)$.

\section{Statistics}

Statistical analyses were performed with SAS (SAS Institute Inc., Cary, NC, USA). Means are given \pm SE.

\section{Factors related to divorce and mate fidelity}

An individual A was considered to have divorced from individual $\mathrm{B}$ if they bred together in year $t$, whereas in year $t+1$ individual $A$ bred with a new partner although its former partner B was still alive. We used GLMM with binomial distribution to test whether the probability of divorce of a pair was related to its breeding success (laying date, clutch size, the proportion of eggs that failed to hatch, number of fledglings) and individual characteristics (age and plumage traits) in year $t$. We set year, male and female identities as random factors. The present paper is mainly based on divorce occurring between the first annual breeding attempt in year $t$ and the first annual breeding attempt in year $t+1$. However, in Swiss barn owls, about $10 \%$ of females produce a second annual clutch (Henry et al., 2013). We therefore examined whether our results based on first annual broods are not blurred by the fact that owls can also divorce between the first and second annual broods (Henry et al., 2013). To this end, we investigated whether producing a second annual brood predicts divorce between first annual broods and also whether changing partner between the first and second annual clutch predicts divorce.

\section{Potential effect of divorce on reproductive success, and differences between successive mates}

We examined the relationship between divorcing and being faithful between years $t$ and $t+1$ on the reproduction in year $t+1$. We ran linear mixed models in which laying date, clutch size and number of fledglings in year $t+1$ were set as dependent variables in separate models. Year and identity of the focal individual were introduced as random factors. To avoid pseudo-replication, faithful males did not appear, as their reproductive success is equal to the reproductive success of their partner. We then analysed the effect of gender by performing the same models with the subset of divorcing individuals alone.

We performed a second type of analysis to test whether reproductive success of focal individuals changed between years $t$ and $t+1$ after having divorced. A similar analysis was performed to examine whether the former mate showed different characteristics (plumage and age) than the new mate following divorce. To do so, we examined the effect of year $(t$ : before divorce, $t+1$ : after divorce) and gender in linear mixed models. Dependent variables were number of fledglings, partner's plumage and age in separate models. Year and focal individual identity were set as random factors.

Model selection was performed by backward elimination of the nonsignificant $(P>0.05)$ terms beginning with the highest order interaction terms. Final models only contained significant effects, and when a two-way interaction term was significant, the main effects involved in the interaction were retained even if nonsignificant. In several models, we included the identity of breeding pairs and of the breeding site, but the number of random factors was then too high for the models to run correctly. Although we refrained from including these random factors, we examined whether using them instead of others modified our conclusions. This was not the case.

\section{Results}

\section{Frequency of mate change}

We found 51 cases of divorce and 166 events of pair fidelity giving a divorce rate of $23.5 \%$. About 634 pairs $(83.6 \%)$ bred only 1 year together in the study area, 82 pairs $(10.8 \%) 2$ years, 27 pairs $(3.6 \%) 3$ years, 12 pairs $(1.6 \%) 4$ years, two pairs $(0.3 \%) 5$ years and one pair $(0.1 \%) 6$ years together. Figure 1 shows the number of mates that each individual secured during the study period. Among individuals that changed partner between successive years, we could demonstrate that it was a divorce in 102 cases ( 51 males and 51 females), and for 245 other males and 167 females that changed mate, we could not demonstrate whether their previous partner was still alive or not. Therefore, mate change (divorce or not) between two successive years occurred in 50\% of females breeding at least twice in the study area (167 of 335 cases) and $60 \%$ of males (245 of 408 cases).

\section{Mate and site fidelity}

When partners broke apart, males stayed more often in their previous reproductive site ( 21 of 51 males changed site, i.e. $41 \%$ ) than females who almost all changed site $\left(96 \% ; 49\right.$ of 51 females; chi-square test: $\chi^{2}=49$, 


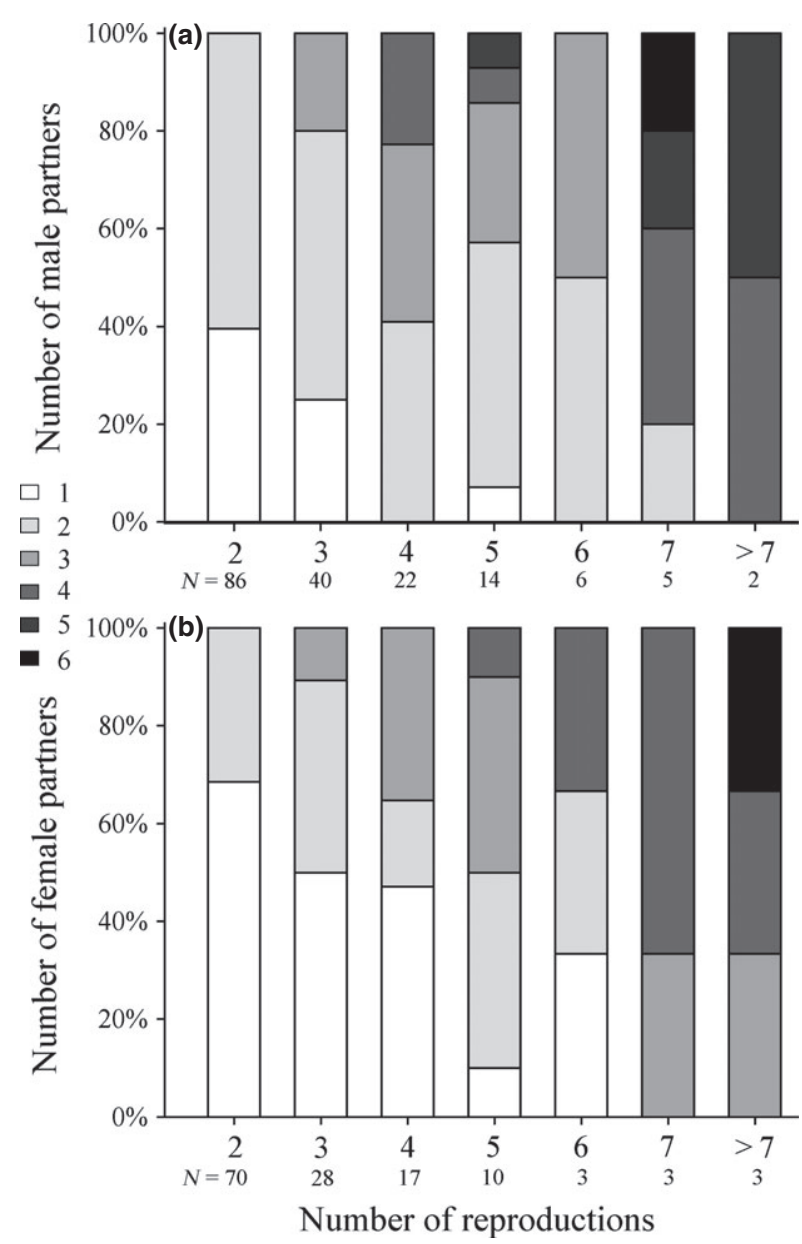

Fig. 1 Number of different partners that (a) female and (b) male barn owls secured during the 26-year study period at the first annual breeding attempts according to the number of years we recorded them as breeders (i.e. 2 to $>7$ ). For each category, the number of individuals is indicated below the number of years recorded as breeders.

$P<0.0001)$. The probability that individuals changed site was higher when divorcing than when faithful to their partner (37 of the 166 faithful pairs changed site, $22 \%$ ) in both males and females (chi-square test: $\chi^{2}=17, P<0.0001$ vs. $\left.\chi^{2}=53, P<0.0001\right)$. In birds that changed site between two consecutive years, the mean $( \pm \mathrm{SE})$ distance between the new and previous site was similar in divorced males $(1.1 \pm 0.2 \mathrm{~km}, N=21)$ as in males that remained with the same partner $(0.8 \pm 0.1 \mathrm{~km}, N=35$; Mann-Whitney $U$-test: $\mathrm{Z}=1.1$, $P=0.28)$, but higher in divorced females $(2.3 \pm 0.3 \mathrm{~km}$, $N=49)$ than in divorced males $(\mathrm{Z}=2.6, P=0.0096)$.

\section{Potential cause of divorce}

Divorce between years $t$ and $t+1$ was more likely in pairs that produced few rather than many fledglings in year $t$ (GLMM with divorce status as dependent variable and as random factors year, male and female identities; $F_{1.33}=17.26, P=0.0002,45$ divorced pairs and 144 faithful pairs; Fig. 2c). Pairs divorced more frequently when males were young rather than old (male age: $F_{1,33}=7.17, P=0.012$; female age: $F_{1,33}=2.28$, $P=0.14$; Fig. 3$)$. In contrast, the probability of divorce was not related to clutch size $\left(F_{1,33}=1.58, P=0.22\right.$; Fig. $2 b)$, laying date $\left(F_{1,33}=0.39, P=0.54\right.$; Fig. 2a), the proportion of eggs that failed to hatch $\left(F_{1,33}=0.78\right.$,
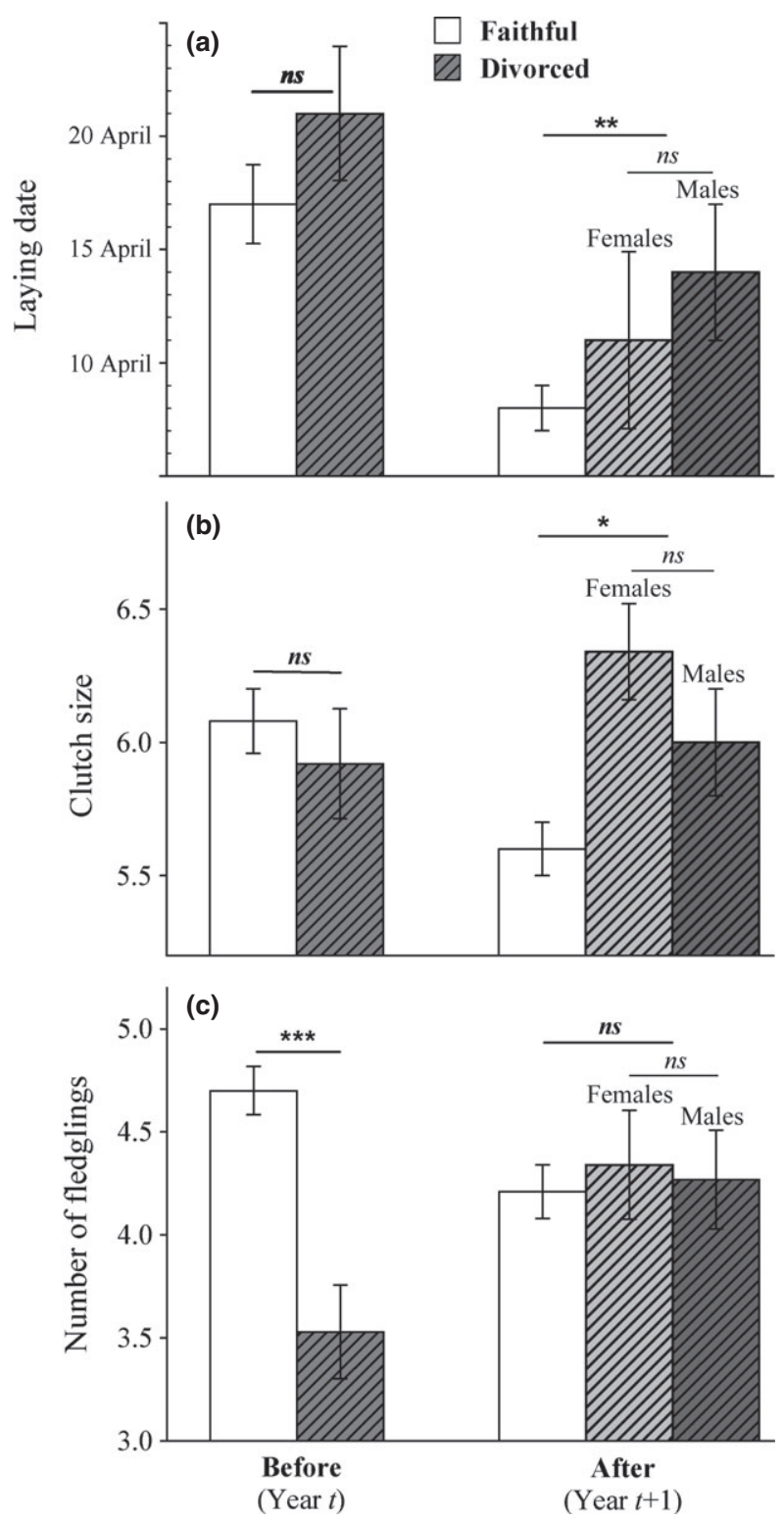

Fig. 2 (a) Laying date, (b) clutch size and (c) number of fledglings of male and female barn owls in relation to status (divorce, faithful) the year before (divorce or nondivorce) and the year after (mean $\pm \mathrm{SE}$ ). *indicates that $P<0.05, * * P<0.01$ and *** $P<0.0001$. 

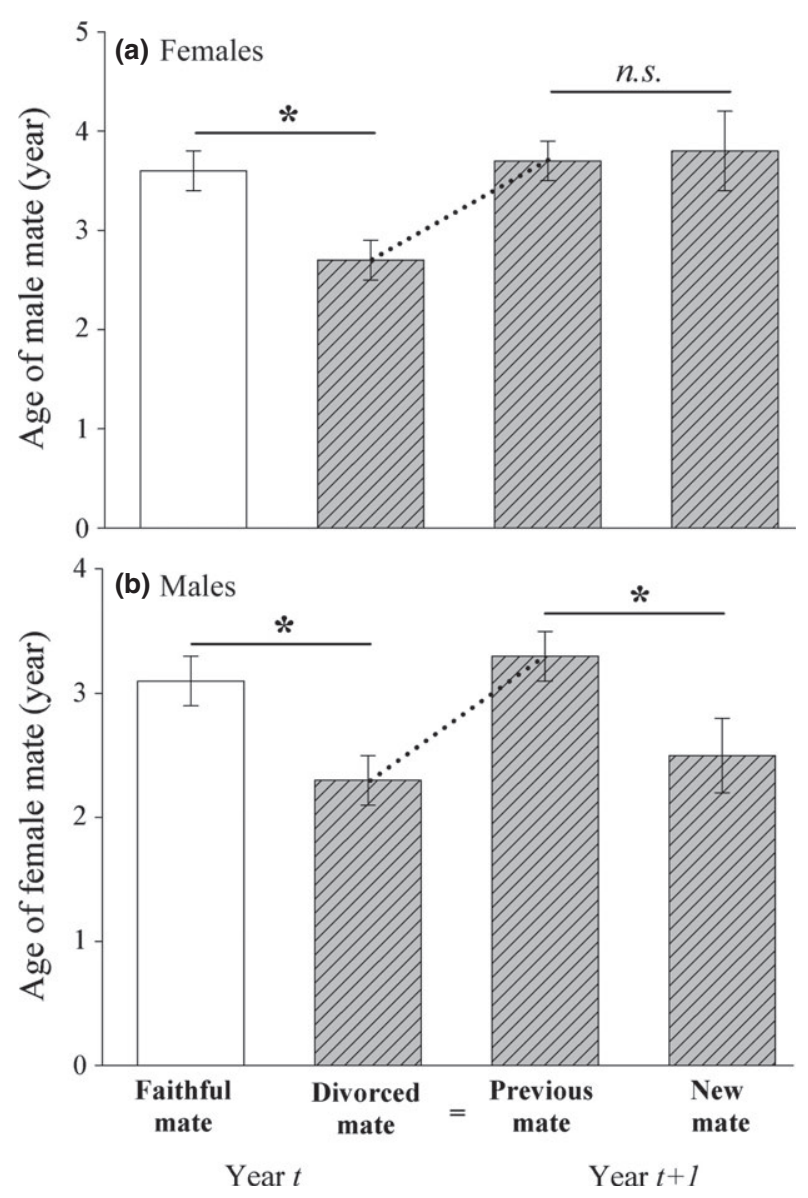

Fig. 3 Age (in years) of female and male barn owl partners in the year before we recorded them to have divorced or bred again together (faithful pairs) and age of their new partner after divorce. Previous mate and divorce mate are the same individuals. *indicates that $P<0.05$.

$P=0.38$ ), and plumage traits (male reddish colour: $F_{1,33}=0.06, \quad P=0.80 ;$ male number of spots: $F$ $1,33=0.94, P=0.34$; male spot diameter: $F_{1,33}=1.17$, $P=0.29$; female reddish colour: $F_{1,33}=0.01, P=0.96$; female number of spots: $F_{1,33}=0.17, P=0.68$; female spot diameter: $\left.F_{1,33}=0.11, P=0.74\right)$. The above results were obtained from a single GLMM, and if we run separate models for each partners' characteristic (age and plumage traits) and each reproductive parameter (laying date, clutch size, proportion of eggs that failed to hatch and number of fledglings), we obtain similar results, with the same two variables being related to the probability of divorce (number of fledglings: $F_{1,43}=15$. 56, $P=0.0003$ and male age: $F_{1,44}=7.30$, $P=0.010$ ). Furthermore, in univariate analyses, the probability of divorce also decreased with female age $\left(F_{1,43}=4.98, \quad P=0.031\right)$. The similarity in plumage traits between the female and male mates did not predict divorce (in a similar analysis: absolute age differ- ence between mates: $F_{1,43}=2.95, P=0.09$; reddish colour absolute difference: $F_{1,43}=0.08, P=0.78$; number of spots absolute difference: $F_{1,43}=0.09, P=0.76$; spot diameter absolute difference: $F_{1,43}=0.11$, $P=0.74)$. For all the above analyses, the random variables year, female and male identities were not significantly related to the probability of divorce in likelihood ratio tests (all $P$-values $>0.1$ ).

To understand which aspect of fledgling success was related to divorce, we performed additional analyses. When considering pairs that produced at least one fledgling, those who produced more fledglings in year $t$ were less likely to divorce between years $t$ and $t+1$ (GLMM: $\quad F_{1,42}=11.00, \quad P=0.002$ ). Furthermore, divorce was more frequent in pairs that failed to produce any fledglings compared to successful pairs (similar GLMM: $F_{1,43}=5.41, P=0.025 ; 10 \%$ of divorcing pairs did not produce any fledglings, while it was the case for only $2 \%$ of pairs remaining faithful). Pairs were more likely to divorce when more offspring died during the rearing period $\left(F_{1,41}=12.81, P=0.009\right.$; pairs that divorced: $1.8 \pm 0.2$ dead offspring; faithful pairs: $1.0 \pm 0.1)$. Mean offspring body mass was not related to the probability of divorcing $\left(F_{1,44}=0.04, P=0.83\right)$.

Pairs that divorced between years $t$ and $t+1$ bred in year $t$ in sites that were as often occupied by breeding barn owls during the 26-year study period as sites of faithful pairs $\left(F_{1,41}=1.19, P=0.28\right.$; probability that sites of divorced pairs were occupied in any year during the study period: $0.59 \pm 0.03$; faithful pairs: $0.63 \pm 0.02$ ). This suggests that the quality of breeding sites in year $t$ may not be a cause of divorce.

Individuals that produced a single annual brood divorced as often as double-brooded individuals, divorce being defined as changing mate between the first annual brood in year $t$ and the first annual brood in year $t+1$ independently of whether females changed mate between the first and second brood in year $t$ (GLMM: $F_{1,44}=1.23, P=0.27$ with year and partner's identity at the first annual breeding attempt in year $t$ as random factors; probability of divorcing in females who produced and did not produce a second annual clutch in year $t$, respectively: $0.31 \pm 0.08$ [1 1 divorced and 24 faithful females] and $0.22 \pm 0.03$ [40 divorced and 142 faithful females]). A similar result applies to males $\left(F_{1,40}=0.44, \quad P=0.51 ; \quad\right.$ respectively: $\quad 0.17 \pm 0.08$ [4 divorced and 19 faithful males] and $0.25 \pm 0.03$ [48 divorced and 145 faithful males]).

Females who changed partner between the first and second annual reproductive attempt in year $t$ divorced more often between years $t$ and $t+1$ (GLMM: $F_{1,20}=5.08, \quad P=0.036$ with year as random factor; probability of divorcing in females that changed partner between first and second clutch: $0.54 \pm 0.14$ [7 divorced and 6 faithful females who came back to their initial mate]; probability of divorcing in females that did not change partner between the first and second annual 
reproductive attempts: $0.15 \pm 0.08$ [three divorced and 17 faithful females]). Two females who divorced between years $t$ and $t+1$ produced their first annual clutch in year $t+1$ with the same partner with whom they produced the second annual clutch in year $t$. All 22 double-brooded males produced the two annual broods with the same partner.

\section{Potential consequences of divorce}

After divorce between years $t$ and $t+1$, individuals breeding with a new partner laid their clutch later in the season in year $t+1$ than reunited faithful pairs (linear mixed model with focal individual as random factor: $F_{1,73}=9.71, P=0.0026$; Fig. $2 a$ ), independently of site change alone $\left(F_{1,88}=0.50, P=0.48\right)$ or in interaction with divorce $\left(F_{1,86}=0.06, P=0.81\right)$. After divorce, the laying date of newly paired males and females did not significantly differ (same model, sex effect: $\left.F_{1,41}=1.89, P=0.18\right)$. We removed age from the model because it was not associated with laying date $\left(F_{1,39}=1.39, P=0.25\right)$.

In year $t+1$, divorced individuals laid larger clutches compared to pairs that remained faithful (linear mixed model with clutch size as dependent variable: $F_{1,70}=4.07, P=0.047$; Fig. $\left.2 \mathrm{~b}\right)$, independently of site change $\left(F_{1,84}=0.47, \quad P=0.49\right)$; we removed laying date and age from the model because these variables were not significantly associated with clutch size $(P$-values $>0.49)$. Males and females who divorced between years $t$ and $t+1$ produced a clutch of similar size in years $t$ and $t+1$ when breeding with another partner (same model, sex effect: $F_{1,39}=1.00, P=0.32$ ).

Faithful pairs and newly paired divorced individuals of both sexes produced a similar number of fledglings in year $t+1$ (another linear mixed model, effect of divorce: $F_{1,71}=0.01, P=0.97$; Fig. $2 \mathrm{c}$; effect of gender of divorced individuals: $\left.F_{1,40}=0.04, P=0.84\right)$. Newly paired males and females hence produced more fledglings after divorce in year $t+1$ than before divorce in year $t$ (year: $F_{1,103}=11.69, P=0.0001$; no effect of gender, alone: $F_{1,103}=0.01, P=0.93$, or in interaction with year: $\left.F_{1,102}=0.04, P=0.85\right)$. Conversely, the probability of producing no fledgling in year $t+1$ was not related to divorce status (GLMM, effect of divorce: $\left.F_{1,86}=0.47, P=0.49\right)$. Mean body mass of nestlings raised in years $t$ and $t+1$ was not related to whether their parents divorced between years $t$ and $t+1$ or remained faithful (year effect $[t$ vs. $t+1]: F_{1,523}=0.57$, $P=0.45$, divorce status: $F_{1,523}=0.01, P=0.98$, interaction year $\times$ divorce: $F_{1,520}=0.57, P=0.42$, interaction year $\times$ divorce $\times$ sex: $\left.F_{1,519}=0.02, P=0.88\right)$.

Individuals that changed site between years $t$ and $t+1$ bred in sites (in year $t+1$ ) that were less often occupied by breeding barn owls during the 26-year study period, but independently of whether they divorced or not between years $t$ and $t+1$ (mixed model with site occupation rate as dependent variable, year and focal individual as random factors: site change: $F_{1,90}=6.87, P=0.010$; divorce: $F_{1,89}=0.62, P=0.43$; sex: $F_{1,89}=1.64, P=0.20$; age: $F_{1,90}=5.58, P=0.020$, occupation rate increasing with age of breeders; no significant interaction).

Divorcing or being faithful between years $t$ and $t+1$ did not affect the female probability to produce a second annual clutch in year $t+1$ (GLMM: $F_{1,47}=1.45$, $P=0.23$; probability of having a second clutch for divorced and faithful females, respectively: $0.13 \pm 0.05$, $N=48$ and $0.17 \pm 0.03, N=151)$. A similar conclusion applies to males (another GLMM: $F_{1,47}=1.90$, $P=0.17$; probability of having a second clutch for divorced and faithful males, respectively: $0.07 \pm 0.03$, $N=45$ and $0.07 \pm 0.02, N=151)$.

\section{Characteristics of new mates}

In year $t+1$, the new female mate of divorced males displayed smaller black spots (linear mixed model: $F_{1,51}=4.82, P=0.033$; Fig. 4 ) and was younger (same
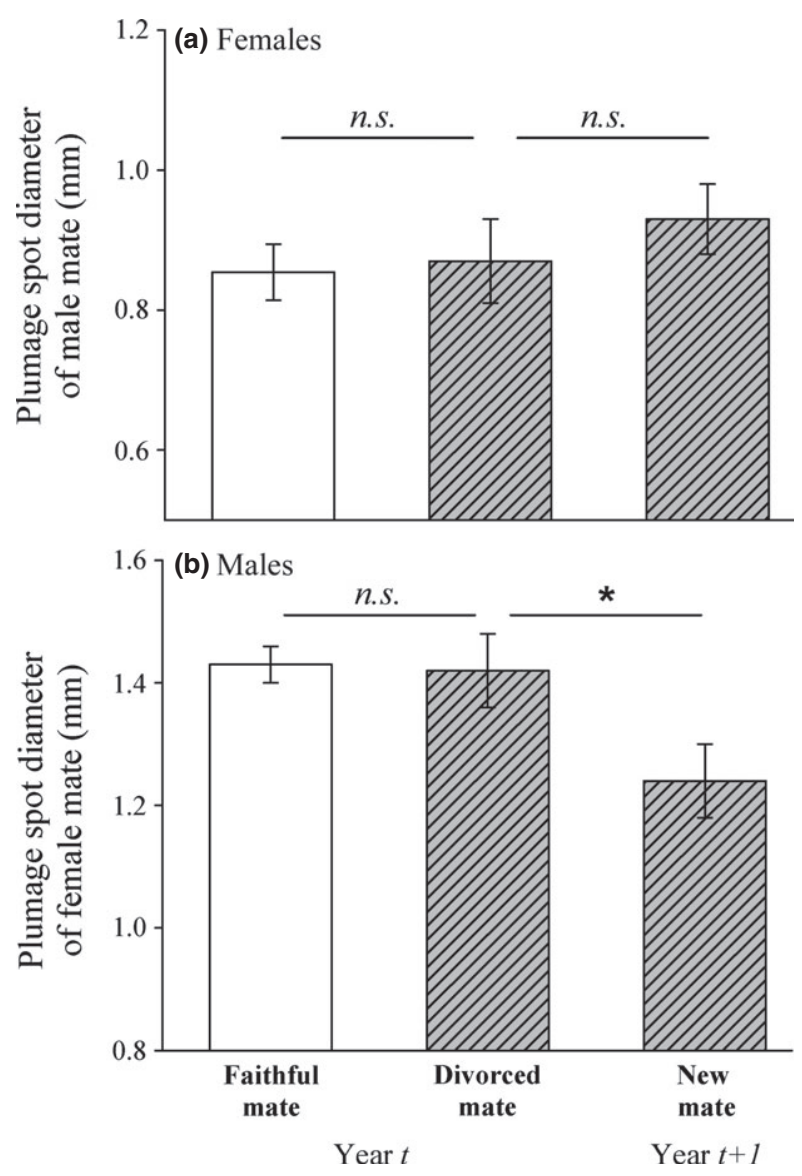

Fig. 4 Diameter (mm) of eumelanic black feather spots of female and male barn owl partners in divorced and faithful pairs and of their new partner after divorce. 
model: $F_{1,51}=5.12, P=0.028$; Fig. 3) than the female with whom these males bred the year before divorcing in year $t$. In contrast, after divorcing, females bred with a male mate of similar age $\left(F_{1,48}=0.71, P=0.40\right)$ and similarly spotted $\left(F_{1,48}=0.62, P=0.43\right)$ as their previous mate. This gender difference was significant, as shown by interactions between focal individual sex and year $(t$ or $t+1)$ in linear mixed models with partner spot diameter and age as dependent variables (respectively, $\quad F_{1,101}=4.55, \quad P=0.035$ and $F_{1,101}=4.17$, $P=0.044$; year and identity of focal individual as random factors). The new and previous partners of individuals that divorced displayed similar number of spots and reddish colour as before divorce in divorced males and females (no effect of year $(t$ or $t+1)$, alone or in interaction with sex of focal individual: all $P$-values $>0.1$ ).

\section{Compatibility or best option?}

The above results suggest that divorce is beneficial for both males and females, as on average individuals of both sexes increase their reproductive success after divorce. We further analysed whether both members of a pair, independently of their sex, significantly increased their success. When a pair divorced, we compared reproductive success achieved in years $t$ and $t+1$ of the divorced individual that was the least successful in year $t+1$. This analysis showed that this individual, whatever its sex, did not produce more fledglings in year $t+1$ compared to year $t$ (paired $t$-test comparing the number of fledglings before and after divorce: $t_{50}=-0.83, P=0.41$; number of fledglings in year $t$ : $3.5 \pm 0.2$, year $t+1$ for the least successful individual of a pair: $3.3 \pm 0.3$ ). In contrast, the most successful individual of a divorced pair did improve reproductive success between years $t$ and $t+1 \quad\left(t_{50}=6.13\right.$, $P<0.0001$; number of fledglings in year $t+1$ : $5.4 \pm 0.2)$.

\section{Reproductive success in relation to the number of years an individual bred with the same partner}

Laying date was not significantly related to the number of years pairs bred together (Fig. 5; $F_{1,151}=1.07$, $P=0.30$ ). In this model, we took into account the number of breeding seasons experienced (i.e. number of first annual clutches produced in previous years) by females $\left(F_{1,158}=23.97, P<0.0001\right.$, estimate: $\left.-2.7 \pm 0.6\right)$ and males $\left(F_{1,151}=0.64, P=0.43\right)$ and the number of years males $\left(F_{1,158}=5.96, P=0.016\right.$, estimate: $\left.-1.9 \pm 0.8\right)$ and females $\left(F_{1,151}=0.37, P=0.54\right)$ spent in the same breeding site. In this model, we also controlled for age of both partners (female age: $F_{1,151}=0.01, P=0.93$; male age: $F_{1,158}=13.06, P=0.0004$, estimate: $-1.4 \pm 0.4$ ).

Clutch size decreased with the number of years faithful partners bred together (Fig. 5; linear mixed model with year and male and female identities as random variables:
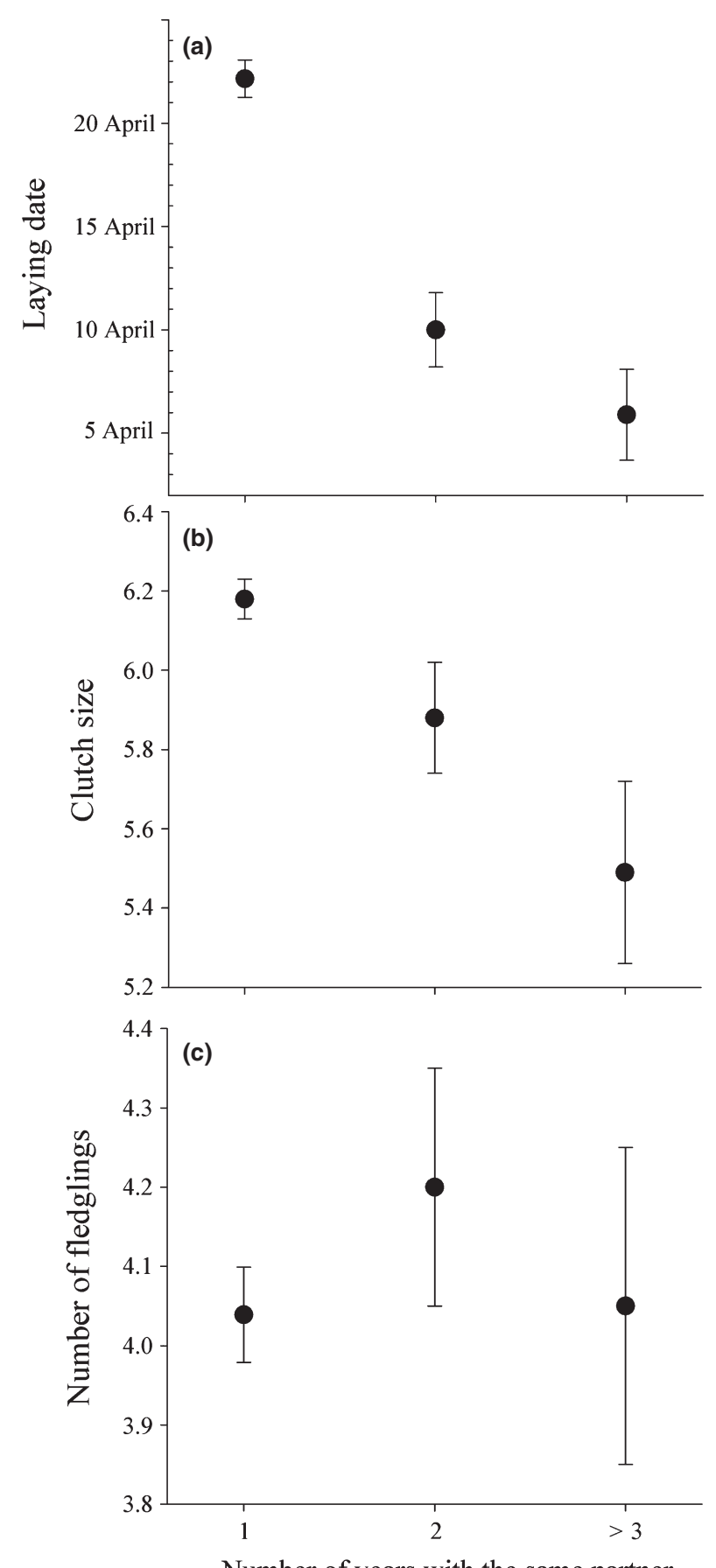

Number of years with the same partner

Fig. 5 (a) Laying date, (b) clutch size and (c) number of fledglings in relation to the number of years barn owls bred with the same partner (mean $\pm \mathrm{SE}$ ). Number of pairs that bred only one year is 745, 2 years 119 , three years 56 . In these panels, we report raw data not statistically controlled for other variables as shown in the result section.

$F_{1,145}=6.82, P=0.010$, controlling for laying date and age of both partners in the model, female age: $F_{1,146}=10.21, P=0.0017$, estimate: $0.10 \pm 0.03$; male 
age: $\quad F_{1,146}=16.55, \quad P<0.0001$, estimate: $-0.09 \pm$ 0.02 ). Clutch size was not significantly related to the number of breeding seasons experienced by male or female partners (same model, respectively: $F_{1,142}=3.17$, $\left.P=0.08 ; F_{1,142}=0.33, P=0.57\right)$, nor to the number of years the male or female partner bred in the same site (respectively, $\quad F_{1,142}=0.24, \quad P=0.63 ; \quad F_{1,142}=0.23$, $P=0.63)$. Note that if we consider only pairs that bred at least three times in the study area (and hence we remove females that bred only once and could not be recorded as faithful or divorcing), we obtain a similar negative association between clutch size and the number of years that partners bred together (similar model: $F_{1,139}=7.18$, $P=0.008, N=123$ pairs).

The number of fledglings was not associated with the number of years that partners bred together (Fig. 5; $\left.F_{1,149}=0.52, P=0.47\right)$, but only with the number of breeding experiences by females $\left(F_{1,160}=9.24\right.$, $P=0.003$, estimate: $0.12 \pm 0.04$; number of breeding experiences of males: $F_{1,149}=0.05, P=0.82$; number of years the male and female partners spent in the same site, respectively: $F_{1,149}=0.05, \quad P=0.09$; $F_{1,149}=0.41, P=0.52$; controlling for age of both partners: female age: $F_{1,149}=0.01, P=0.97$; male age: $\left.F_{1,149}=0.01, P=0.95\right)$. Hence, the number of eggs that failed to produce a fledgling decreased with the number of breeding seasons shared with the same partner $\left(F_{1,143}=4.74, P=0.031\right)$.

\section{Discussion}

Our study reports four major results. First, divorce happened mainly after barn owls achieved a poor reproductive success. Second, by acquiring a new mate the following breeding season, usually one pair member, male or female, succeeded in restoring reproductive success. Third, nestling survival was higher when raised by pairs that remained faithful for many rather than few years. Finally, males who divorced secured a new female mate who displayed an ornament (in the form of black eumelanic feather spots) to a lower degree compared to the former mate.

\section{Potential causes of divorce}

In this population of barn owls, extra-pair fertilization being very rare (Henry et al., 2013), the only possibility to mate with another partner is to divorce. Reproductive success was the best predictor of divorce, because pairs were more likely to divorce if failing to produce any fledglings and if among successful pairs they produced fewer fledglings. Reproductive success was the only reproductive parameter to be associated with divorce, because clutch size, proportion of eggs that failed to hatch, laying date, offspring body condition and producing one or two annual broods were not associated with the probability of divorcing. Our results confirm the general trend observed in birds about a potential role of reproductive success in determining whether pairs remain faithful or break up (Dubois $\mathcal{E}$ Cezilly, 2002). Because variation in reproductive success can be explained by several factors such as the quality of parental care (Moody et al., 2005), mate quality or compatibility (Tregenza \& Wedell, 2000), parental age (and hence experience) (Pampus et al., 2005), territory quality (Garcia-Navas \& Sanz, 2011), knowledge of territory that improves with the duration of site fidelity (Bai \& Severinghaus, 2012) and annual variation in food resources, all these factors could account for the observation that divorce is more frequent after a poor reproductive season.

We found that the probability of divorce was higher in young than in old males, while in females a weaker relationship was detected. The statistical effect of male age was independent of reproductive success, suggesting that age has an additional effect on divorce. In contrast, we found no evidence about a role of territory quality in the decision to divorce, although we are aware that our measure of territory quality, measured by the number of years breeding sites were occupied by breeding barn owls over the entire study period, may not catch all the variance in territory quality.

Birds that divorced and those remaining faithful were themselves, as well as their mate, similarly plumaged. This suggests that barn owls do not divorce to secure a new mate displaying a consistently different plumage (e.g. darker or lighter coloured). Thus, although we reported evidence that pairing with respect to melaninbased coloration is not random (Roulin, 1999; Roulin \& Altwegg, 2007), divorce may not be triggered by the plumage characteristics of the two partners. To the best of our knowledge, only one study investigated whether the probability of reuniting with a mate is associated with secondary sexual characters. In least auklet (Aethia pusilla), males displaying larger facial plumes divorced less often than males with smaller plumes (Jones $\&$ Montgomerie, 1991).

\section{Who does initiate divorce?}

A key question in the study of divorce is who of the female and male initiates divorce. Usually, females are considered to initiate divorce more often than males (review in Cézilly et al., 2000). Unfortunately, in a nocturnal bird such as the barn owl, it is very difficult to identify the sequences that lead to divorce as done by field observations in other species such as in the great skua (Catharacta skua) (Otter \& Ratcliffe, 1996; Catry et al., 1997). However, we observed that reunited pairs and divorced males showed strong site fidelity or moved to a nearby site that may still be in the same territory (in our study area, home range size ranges from 93 to 804 ha (Sandercock et al., 2000; Arlettaz et al., 2010). Conversely, most divorced females left to 
breed in another site (two of 51,4\%), a very frequent situation in birds (e.g. Blondel et al., 2000; Garcia-Navas \& Sanz, 2011). This suggests that in most cases, barn owl males expel their mate (e.g. Jeschke et al., 2007) or females initiate divorce by leaving the breeding site.

\section{Potential costs and benefits of divorce}

To explain the frequent occurrence of divorce in animal populations, evolutionary biologists have assumed that divorce has an adaptive function because individuals often divorce after a poor reproductive season (Dubois \& Cezilly, 2002). Accordingly, in the barn owl, divorced individuals produced a significantly larger number of fledglings after divorce in year $t+1$ compared to before divorce in year $t$. This suggests that divorce may be adaptive, and is not resulting from an accidental loss of the partner (Dhondt \& Adriaensen, 1994) or from the antagonist interactions with a third individual expelling one member of the couple as observed in mammals (Taborsky \& Taborsky, 1999; Lardy et al., 2011). However, divorcing to restore reproductive success may also entail costs. For instance, in the Australasian gannet (Morus serrator) (Ismar et al., 2010), blue tit (Parus caeruleus) (Pampus et al., 2005) and blackbird (Turdus merula) (Wysocki, 2006), reproductive success can be lower in divorced than in faithful individuals. In the barn owl, divorced individuals bred later in the season than faithful individuals, and although they produced larger clutches, the number of fledglings was similar between divorced and faithful birds. This suggests that acquiring a new mate takes time. This may be explained by the fact that divorced individuals are not particularly attractive to potential mates or are relegated to poorer-quality territories, not because of divorce per se but as a cost of changing site, which frequently occurs after a divorce (Mills, 1973; Johnston \& Ryder, 1987). Also, fewer high-quality mates may be available after a divorce (Choudhury, 1995). Accordingly, divorced males secured a new female mate who displayed smaller black spots and was younger than the female with whom they were paired the previous year. Because the size of black spots is a honest genetic signal of quality particularly in females (Roulin \& Ducrest, 2011), we conclude that in males divorcing entails the cost of securing a poorer-quality mate. Furthermore, individuals that changed site between years $t$ and $t+1$ obtained a poorer-quality site, and because divorce is most often concomitant with a change of breeding site, divorcees have fewer choices where to breed and hence are relegated to the poorer-quality sites.

Although divorce entails costs and benefits, the net benefit should be positive. This can be achieved in two major different ways. A first way to improve reproductive success by divorcing is to secure a higher-quality mate (better option hypothesis) or a compatible mate (incompatibility hypothesis). To discriminate between these two hypotheses, researchers have traditionally collected long-term data (as we did) to examine specific predictions. Indeed, under the 'better option hypothesis', divorce is initiated by one of the two partners to secure a higher-quality partner (Catry et al., 1997). Therefore, only the individual that initiates divorce should increase reproductive success. Under the 'incompatibility hypothesis', pairs break up because partners are not compatible. Divorce is therefore a mutual decision and by divorcing the two partners look for a compatible mate so that they are both predicted to increase reproductive success following divorce (Choudhury, 1995). In line with the incompatibility hypothesis', we found that both males and females increased reproductive success after divorcing. The finding that after divorce males secured a female displaying smaller black spots is against the 'better option hypothesis' that would have predicted the opposite result, namely that males acquire a more heavily spotted female mate after divorce. Although on average males and females restored reproductive success after divorce, this does not necessarily mean that divorce is always beneficial for both members of a pair. Indeed, in the barn owl, only one of the two partners usually improved reproductive success after divorce. As a consequence, we cannot firmly exclude the 'better option hypothesis'. A better test would be to compare reproductive success before and after divorce in individuals (males or females) who initiated divorce and their mate. This is unfortunately not possible, because we do not know for each pair which mate initiated divorce.

\section{Adaptive function of long-term pair-bond}

In many long-lived species such as in seabirds, partners are faithful lifelong (Bried \& Jouventin, 2002). In these species that produce few high-quality rather than many low-quality offspring, reproductive success is determined by a high coordination between partners that can be achieved only after having tended a number of broods as shown experimentally in oystercatchers (Haematopus ostralegus) (van de Pol et al., 2006). Interestingly, in the barn owl, we found the same pattern with pairs being more efficient in their reproductive activities after having bred a higher number of years together. Specifically, fewer nestlings died in pairs with long-term compared to short-term pair-bond, suggesting that partners are more coordinated after having bred together more years. We would thus expect that despite about $23.5 \%$ of the pairs divorce, when reproductive success in year $t$ is good barn owls actively try to pair again with the same partner in year $t+1$. Accordingly, among 13 females who deserted their family half-way through the rearing period to remate the same season with a 
yearling male in order to produce a second annual breeding attempt, six of them $(46 \%)$ came back to their previous mate to produce their first annual brood in year $t+1$. Therefore, in many cases, females change mate between the first and second annual breeding attempts not because the first male is of poor quality or incompatible but for other reasons such as accelerating the production of the second brood rather than waiting that parental duties at the first nest are completed (Roulin, 2002). The effect of long-term pair-bond on nestling survival is explained by the fact that after divorcing owls produce clutches that are too optimistic and hence not optimal. By retaining a high-quality mate, owls are therefore better able to optimize investment in reproduction probably because partners are better coordinated.

We found that yearling males were more likely to divorce than older males. We do not think that the reason is that females divorce because they are able to phenotypically discriminate yearling males from adult ones. Indeed, between the first and second year of age, both males and females become only slightly paler reddish, whereas spots slightly increase in size in females but not in males (Dreiss \& Roulin, 2010). We rather think that adult males had more time to find a compatible mate, and hence are faithful in order to improve coordination and as a consequence are less likely to divorce than yearling males.

\section{Conclusion}

Our study suggests that barn owls divorce when pairs achieve a poor reproductive success. Divorce is thus an adaptive response to restore reproductive success. This decision nevertheless entails a number of costs including breeding later in the season and securing a female of poorer quality as assessed by the degree of heritable melanin-based coloration and age. Once reproductive success is restored, owls have to actively maintain pair-bond to enhance coordination, which allow partners to better optimize investment in reproduction.

\section{Acknowledgments}

We are grateful to Miguel Dos Santos and Manuel Pompini for help. We are grateful to the Swiss National Science Foundation for having granted this study and to two anonymous reviewers for useful comments.

\section{References}

Altwegg, R., Roulin, A., Kestenholz, M. \& Jenni, L. 2003. Variation and covariation in survival, dispersal, and population size in barn owls Tyto alba. J. Anim. Ecol. 72: 391-399.

Arlettaz, R., Krähenbühl, M., Almasi, B., Roulin, A. \& Schaub, M. 2010. Wildflower areas within revitalized agricultural matrices boost small mammal populations but not breeding barn owls. J. Ornithol. 151: 553-564.

Bai, M.L. \& Severinghaus, L.L. 2012. Disentangling site and mate fidelity in a monogamous population under strong nest site competition. Anim. Behav. 84: 251-259.

Black, J.M. 2001. Fitness consequences of long-term pair bonds in barnacle geese: monogamy in the extreme. Behav. Ecol. 12: 640-645.

Blondel, J., Perret, P. \& Galan, M.J. 2000. High divorce rates in Corsican blue tits: how to choose a better option in a harsh environment. Oikos 89: 451-460.

Bried, J. \& Jouventin, P. 2002. Site and mate choice in seabirds: an evolutionary approach. In: Biology of Marine Birds (E.A. Schreiber \& J. Burger, eds), pp. 263-305. CRC Press, Boca Raton, FL.

Catry, P., Ratcliffe, N. \& Furness, R.W. 1997. Partnerships and mechanisms of divorce in the great skua. Anim. Behav. 54: 1475-1482.

Cézilly, F., Préault, M., Dubois, F., Faivre, B. \& Patris, B. 2000. Pair-bonding in birds and the active role of females: a critical review of the empirical evidence. Behav. Process. 51: 83-92.

Chausson, A., Henry, I., Almasi, B. \& Roulin, A. 2014. Barn owl (Tyto alba) breeding biology in relation to breeding season climate. J. Ornithol. 155: 273-281.

Choudhury, S. 1995. Divorce in birds: a review of the hypotheses. Anim. Behav. 50: 413-429.

Coulson, J.C. 1966. The influence of the pair-bond and age on the breeding biology of the kittiwake gull Rissa tridactyla. $J$. Anim. Ecol. 35: 269-279.

Coulson, J.C. 1972. The significance of the pair-bond in the kittiwake. Proc. Int. Ornithol. Congr. 25: 424-433.

Davies, N.B. 1989. Sexual conflict and the polygyny threshold model. Anim. Behav. 38: 226-234.

Davis, L.S. 1988. Coordination of incubation routines and mate choice in Adélie penguins (Pygoscelis adeliae). Auk 105: 428-432.

Dhondt, A.A. 2002. Changing mates. Trends Ecol. Evol. 17: 5556.

Dhondt, A.A. \& Adriaensen, F. 1994. Causes and effects of divorce in the blue tit Parus caeruleus. J. Anim. Ecol. 63: 979987.

Dreiss, A.N. \& Roulin, A. 2010. Age-related change in melanin-based coloration of Barn owls (Tyto alba): females that become more female-like and males that become more male-like perform better. Biol. J. Linn. Soc. 101: 689-704.

Dubois, F. \& Cezilly, F. 2002. Breeding success and mate retention in birds: a meta-analysis. Behav. Ecol. Sociobiol. 52: 357-364.

Ens, B.J., Safriel, U.N. \& Harris, M.P. 1993. Divorce in the long-lived and monogamous oystercatcher, Haematopus ostralegus - Incompatibility or choosing the better option. Anim. Behav. 45: 1199-1217.

Frey, C., Sonnay, C., Dreiss, A. \& Roulin, A. 2011. Habitat, breeding performance, diet and individual age in Swiss barn owls (Tyto alba). J. Ornithol. 152: 279-290.

Garcia-Navas, V. \& Sanz, J.J. 2011. Females call the shots: breeding dispersal and divorce in blue tits. Behav. Ecol. 22: 932-939.

Henry, I., Antoniazza, S., Dubey, S., Simon, C., Waldvogel, C., Burri, R. et al. 2013. Multiple paternity in polyandrous barn owls (Tyto alba). PLOS ONE 8: e80112. 
Ismar, S.M.S., Daniel, C., Stephenson, B.M. \& Hauber, M.E. 2010. Mate replacement entails a fitness cost for a socially monogamous seabird. Naturwissenschaften 97: 109-113.

Jeschke, J.M., Wanless, S., Harris, M.P. \& Kokko, H. 2007. How partnerships end in guillemots Uria aalge: chance events, adaptive change, or forced divorce? Behav. Ecol. 18: 460-466.

Johnston, V.H. \& Ryder, J.P. 1987. Divorce in Larids: a review. Waterbirds 10: 16-26.

Jones, I.L. \& Montgomerie, R. 1991. Mating and remating of least auklets (Aethia pusilla) relative to ornamental traits. Behav. Ecol. 2: 249-257.

Lack, D. 1968. Ecological Adaptations for Breeding in Birds. Methuen, London.

Lardy, S., Cohas, A., Figueroa, I. \& Allaine, D. 2011. Mate change in a socially monogamous mammal: evidences support the "forced divorce" hypothesis. Behav. Ecol. 22: 120-125.

Mills, J.A. 1973. The influence of age and pair bond on the breeding biology of the Red-billed Gull, Larus novaehollandiae scopulinus. J. Anim. Ecol. 42: 147-163.

Moody, A.T., Wilhelm, S.I., Cameron-MacMillan, M.L., Walsh, C.J. \& Storey, A.E. 2005. Divorce in common murres (Uria aalge): relationship to parental quality. Behav. Ecol. Sociobiol. 57: $224-230$.

Otter, K. \& Ratcliffe, L. 1996. Female initiated divorce in a monogamous songbird: abandoning mates for males of higher quality. Proc. R. Soc. Lond. B Biol. Sci. 263: 351-355.

Pampus, M., Schmidt, K.-H. \& Wiltschko, W. 2005. Pair bond and breeding success in blue tits Parus caeruleus and great tits Parus major. Ibis 147: 92-108.

van de Pol, M., Heg, D., Bruinzeel, L.W., Kuijper, B. \& Verhulst, S. 2006. Experimental evidence for a causal effect of pair-bond duration on reproductive performance in oystercatchers (Haematopus ostralegus). Behav. Ecol. 17: 982-991.

Roulin, A. 1999. Nonrandom pairing by male barn owls (Tyto alba) with respect to a female plumage trait. Behav. Ecol. 10: 688-695.

Roulin, A. 2002. Offspring desertion by double-brooded female Barn owls (Tyto alba). Auk 119: 515-519.

Roulin, A. 2004. Proximate basis of the covariation between a melanin-based female ornament and offspring quality. Oecologia 140: 668-675.

Roulin, A. \& Altwegg, R. 2007. Breeding rate is associated with pheomelanism in male and with eumelanism in female barn owls. Behav. Ecol. 18: 563-570.
Roulin, A. \& Dijkstra, C. 2003. Genetic and environmental components of variation in eumelanin and phaeomelanin sex-traits in the barn owl. Heredity 90: 359-364.

Roulin, A. \& Ducrest, A.L. 2011. Association between melanism, physiology and behaviour: a role for the melanocortin system. Eur. J. Pharmacol. 660: 226-233.

Roulin, A., Richner, H. \& Ducrest, A.L. 1998. Genetic, environmental and condition-dependent effects on female and male plumage ornamentation. Evolution 52: 1451-1460.

Roulin, A., Jungi, T.W., Pfister, H. \& Dijkstra, C. 2000. Female barn owls (Tyto alba) advertise good genes. Proc. Biol. Sci. 267: 937-941.

Roulin, A., Riols, C., Dijkstra, C. \& Ducrest, A.L. 2001. Female plumage spottiness and parasite resistance in the barn owl (Tyto alba). Behav. Ecol. 12: 103-110.

Roulin, A., Altwegg, R., Jensen, H., Steinsland, I. \& Schaub, M. 2010. Sex-dependent selection on an autosomal melanic female ornament promotes the evolution of sex ratio bias. Ecol. Lett. 13: 616-626.

Rowley, I. 1983. Re-Mating in Birds. Cambridge University Press, Cambridge.

Sandercock, B.K., Lank, D.B., Lanctot, R.B., Kempenaers, B. \& Cooke, F. 2000. Ecological correlates of mate fidelity in two Arctic-breeding sandpipers. Can. J. Zool. 78: 1948-1958.

Sergio, F. \& Newton, I. 2003. Occupancy as a measure of territory quality. J. Anim. Ecol. 72: 857-865.

Streif, M. \& Rasa, O.A.E. 2001. Divorce and its consequences in the common blackbird Turdus merula. Ibis 143: 554-560.

Taborsky, B. \& Taborsky, M. 1999. The mating system and stability of pairs in kiwi Apteryx spp. J. Avian Biol. 30: 143-151.

Taylor, I.R. 1993. Age and sex determination of barn owls Tyto alba alba. Ringing Migr. 14: 94-102.

Tregenza, T. \& Wedell, N. 2000. Genetic compatibility, mate choice and patterns of parentage. Mol. Ecol. 9: 1013-1027.

Wysocki, D. 2006. Factors affecting the between-season divorce rate in the urban populations of the European blackbird Turdus merula in north-western Poland. Acta. Ornithol. 41: $71-78$.

Received 20 December 2013; revised 25 March 2014; accepted 26 March 2014 